\title{
Afonso Taunay, dicionarista científico
}

\author{
Gildo Magalhães \\ Professor Titular Departamento de História FFLCH/USP \\ Professor Colaborador da Universidade de Lisboa \\ gildomsantos@hotmail.com
}

Resumo: $\mathrm{O}$ historiador Afonso Taunay foi também um atento dicionarista de termos científicos e técnicos, aspecto pouco conhecido atualmente. Nesta resenha são apresentados três trabalhos seus, com destaque para suas posições nacionalistas que enfatizam a necessidade de dicionarizar assuntos já recorrentes em sua época, muitos deles ligados com inovações e áreas de estudos que se desenvolveram na primeira metade do século 20.

Palavras-chave: Afonso Taunay; lexicografia científica; nacionalismo.

\section{Afonso Taunay, scientific lexicographer}

Abstract: Historian Afonso Taunay was also an attentive dictionary writer of scientific and technical terms, an aspect little known today. In this review, three of his works are presented, with emphasis on his nationalist positions that emphasize the need to register subjects already recurring in his time, many of them connected with innovations and areas of studies that were developed in the first half of the 20th century.

Keywords: Afonso Taunay; lexicography; nationalism.

Introdução: Afonso d'Escragnolle Taunay

O professor, historiador, tradutor e lexicógrafo Afonso d'Escragnolle Taunay (Florianópolis, 11-06-1876 - São Paulo, 20-03-1958) era filho de Alfredo d'Escragnolle Taunay, Visconde de Taunay, e Cristina Teixeira Leite Taunay. Cursou a Escola Politécnica do Rio de Janeiro, onde se formou em Engenharia Civil em 1900. Tornou-se professor auxiliar de física e química da Escola Politécnica de São Paulo em 1904 e 
professor catedrático na mesma Escola a partir de 1910, onde lecionou Física Experimental, acumulando a docência acadêmica com aulas de ciências no Colégio São Bento. Exerceu vários cargos públicos, tais como diretor do Museu Paulista de 1917 a 1946, gestão na qual foi feita a transição do que incluía a seção de História Natural para o Museu de Zoologia da Universidade de São Paulo, permanecendo o Museu Paulista como o atual museu histórico com esse nome. ${ }^{1}$ Organizou ainda o Museu Republicano de Itu, também pertencente à USP.

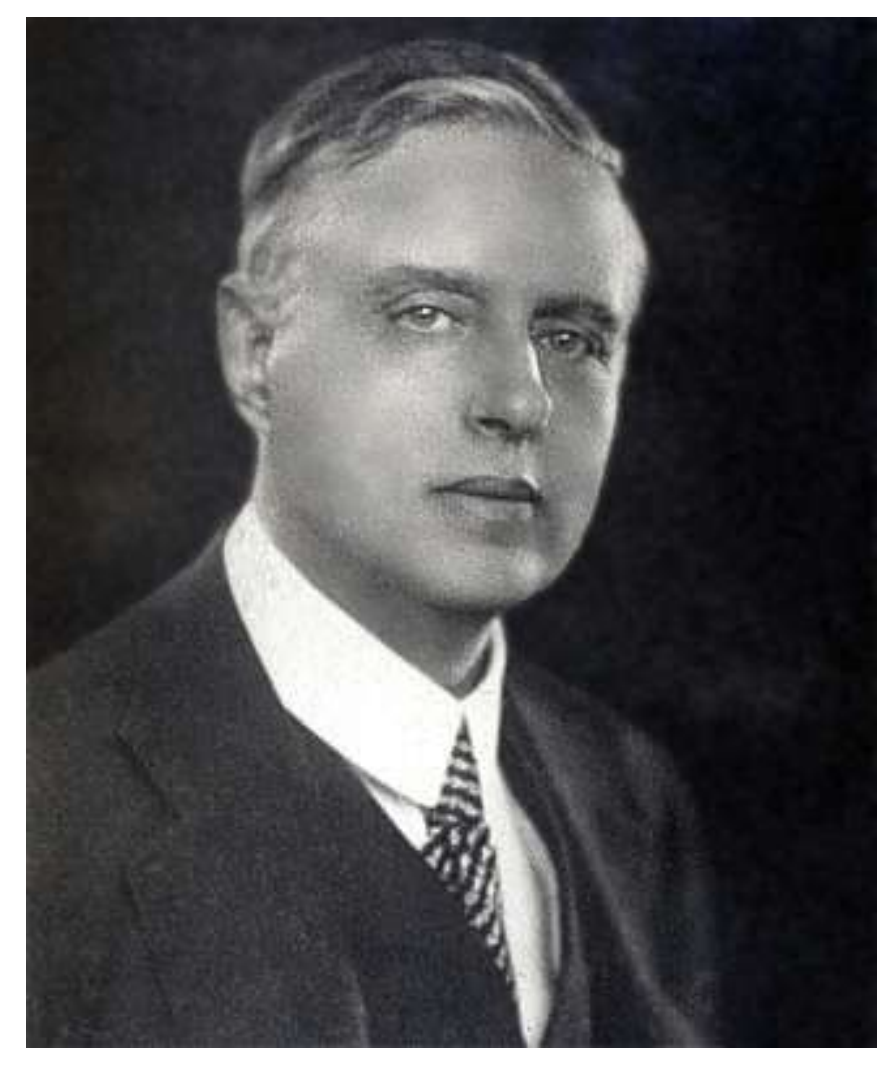

Afonso Taunay. Fonte: Wikimedia Commons

Foi também diretor dos Museus do Estado de São Paulo desde 1923, encarregado do Governo Federal para reorganizar a Biblioteca e o Arquivo do Ministério das Relações Exteriores em 1930, professor na Faculdade de Filosofia, Ciências e Letras, da Universidade de São Paulo entre 1934 e 1937. Foi membro do Instituto Histórico e Geográfico Brasileiro, do Instituto Histórico de São Paulo, da Academia Paulista de Letras, da Academia Brasileira de Letras (1929) e da Academia Portuguesa de História.

\footnotetext{
${ }^{1}$ Para uma análise da trajetória do Museu Paulista, ver ALVES, Ana Maria de Alencar, O Ipiranga apropriado (São Paulo: Humanitas, 2001)
} 


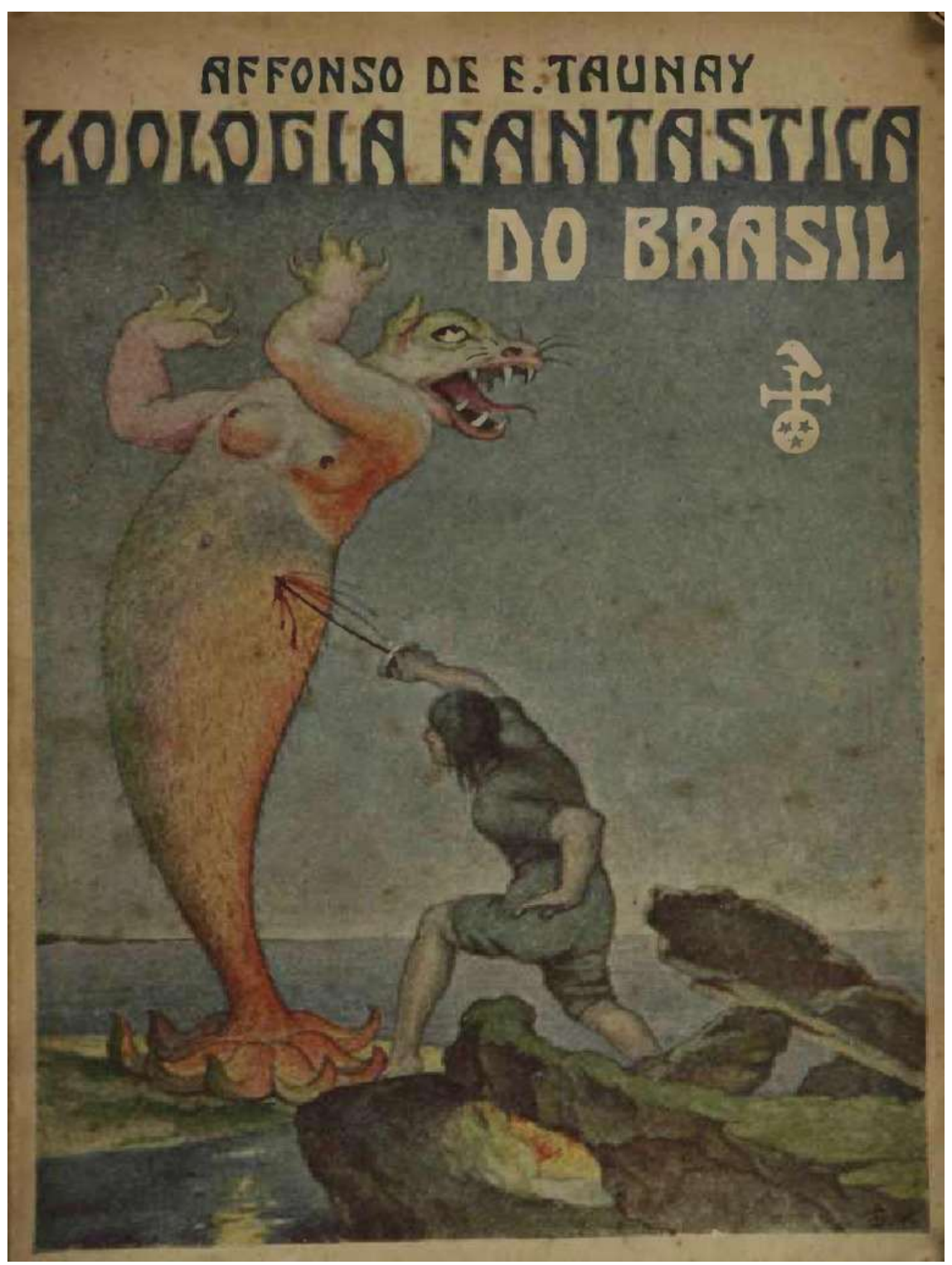

Zoologia fantástica do Brasil (séculos XVI e XVII). São Paulo: Melhoramentos e Weiszflog, 1934. Fonte: https:// digital.bbm.usp.br/

Afonso Taunay especializou-se no estudo dos bandeirantes (seguindo uma linha de pesquisa inaugurada por Capistrano de Abreu) e na história da literatura, da ciência e da arte no Brasil, destacando-se em sua vasta produção historiográfica a História Geral das Bandeiras Paulistas e a História do café. Sua vasta cultura permitiu-lhe preparar reedições comentadas de autores como Bartolomeu de Gusmão e outros. A atenção dada por Taunay aos vocábulos oriundos da cultura popular o levou para campos etnográficos, como exemplificado por sua Zoologia Fantástica do Brasil. 
O que tem sido menos conhecida foi a luta de Taunay como lexicógrafo, especializado na terminologia científica e técnica. Esta sua atividade representou uma crítica incessante contra os dicionaristas portugueses, que então dominavam o Brasil e o mercado editorial, mas ignoravam as especificidades brasileiras.

Vamos a seguir apresentar sucintamente três dessas obras, comentando-as em alguns pontos para ilustrar sua contribuição como dicionarista científico.

\section{Léxico de termos técnicos e científicos ainda não apontados nos dicionários da língua portuguesa ${ }^{2}$}

Esse trabalho inaugura a série de léxicos preparados por Affonso d'E. Taunay, imediatamente antes do Lexico de Lacunas - Subsidios para os diccionarios da língua portugueza (Tours: Imprimerie E. Arnault, 1914).

Na nota introdutória ao volume, Taunay chama a atenção para as deficiências dos dicionários de português em termos da linguagem vulgar, e mais ainda no que tange ao vocabulário técnico e científico. Para ele, isto se deve ao contínuo progresso das ciências, ao desenvolvimento e aperfeiçoamento das indústrias e invenções e à criação de novas tecnologias. Não escapou destas injunções negativas nem o que Taunay considera o melhor dicionário da língua, o de Caldas Aulete muito superior aos congêneres, como o Moraes, que ele desqualifica pelas suas "ingênuas definições". ${ }^{3}$ Por conta desse desenvolvimento acelerado, cita o filólogo Cândido de Figueiredo, que conseguiu apontar trinta mil palavras não catalogadas antes, das quais cerca de dez mil seriam de termos científicos. ${ }^{4}$ Mesmo assim, "humildes pesquisadores" teriam ainda muito a garimpar, como o próprio Taunay alega, já que, em suas palavras, usou apenas suas poucas folgas deixadas pelas "árduas obrigações diárias".

Resultaram desse esforço cerca de cinco mil e quinhentos vocábulos que ainda não haviam sido registrados e que o autor retirou principalmente do Nouveau Larousse Illustré, da Encyclopaedia Britannica, do Diccionario de Medicina, de Littré e Gilbert, do dicionário de química de Nurtz, além de livros de química escritos por cientistas bem conhecidos na época, como os tratados de química orgânica de Berthelot e Jungfleisch.

\footnotetext{
${ }^{2}$ Lexico de termos technicos e scientificos ainda não apontados nos diccionarios da língua portugueza. São Paulo: Annuario da Escola Polytechnica de S. Paulo. XII (Separata, 154 p.), 1909 (o exemplar consultado contém dedicatória de próprio punho do autor, datada de 1911).

${ }^{3}$ Francisco Júlio de Caldas Aulete (Lisboa, 1823 - Lisboa, 1878), professor, lexicógrafo e polí$\underline{\text { tico }}$ português, autor de diversos livros didáticos e iniciador do Dicionário Contemporâneo da Língua

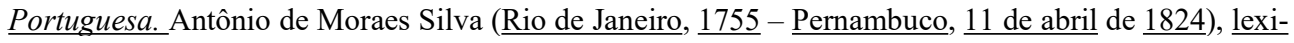
cólogo brasileiro, diplomado em direito civil e canónico pela Universidade de Coimbra, sua principal obra é o Dicionário da Lingua Portuguesa), que na sua edição original se intitulava Diccionario da Lingua Portugueza composto pelo Padre D. Rafael Bluteau, reformado, e accrescentado por Antonio de Moraes Silva (Lisboa, 1789).

${ }^{4}$ António Pereira Cândido de Figueiredo (Lobão da Beira 1846 - Lisboa, 1925), filólogo e escritor português, autor do Novo Dicionário da Língua Portuguesa, originalmente publicado em 1899 e depois alvo de múltiplas reedições até a $25^{\text {a }}$, em 1996.
} 
Em sua formação de engenheiro civil e professor da Escola Politécnica de São Paulo, certamente Taunay lidava com termos científicos e técnicos que, devido à abrangência do currículo de engenharia da época, incluíam aqueles utilizados na então denominada História Natural. Quando se verifica o teor da pesquisa de Taunay, sem dúvida resultam muitos termos das ciências naturais ainda não dicionarizados, compreendendo física, química, mineralogia, geologia, biologia geral, botânica, zoologia, meteorologia, astronomia e, mais raramente, matemática. A estas ajuntam-se vocábulos da medicina em suas várias especialidades, especialmente os relacionados com distúrbios e doenças, assim como uma série grande de palavras oriundas de campos da técnica, que abrangem termos náuticos, instrumentos variados e os diversos ofícios praticados por técnicos e artesãos. Há também algumas incursões pela engenharia, além de termos industriais.

Como alguns exemplos típicos dessas preocupações lexicográficas de Taunay, podem ser citados, usando as definições por ele dadas e para ficar apenas na letra A: $a b a$ (termo náutico para a costa que limita um porto ou a margem de um rio), abrachiocephalo (abraquiocéfalo, indivíduo teratológico caracterizado pela ausência de braços e cabeça); alona (nome químico genérico designando um composto que encerra uma cetona e um aldeído); amaxophobia (amaxofobia, temor dos veículos).

Nomes hoje corriqueiros e que à época eram relativamente desconhecidos surgem em meio a termos mais especializados, como anticorpo (como sendo substância que surge no soro de um animal injetado de micróbios patogênicos e que tem a propriedade de imobilizar ou destruir os elementos parasitários), ou o termo, muito comum na construção civil, de amarração (modo pelo qual as pedras ou tijolos se prendem entre si nas alvenarias e cantarias). Será o caso também de trena (na época, fita de aço ou pano, de que se servem os agrimensores para medir distâncias entre estações e visadas), cujo significado básico ainda é o mesmo hoje em dia.

Taunay vai, no entanto, para além das ciências naturais, acrescentando vocábulos oriundos das ciências humanas, como ocorre com anthropocentrismo (antropocentrismo, sistema que considera o homem como centro do Universo) e da filosofia, tal como spenciarianismo (sistema filosófico do inglês Herbert Spencer). A história e geografia também recebem acréscimos, como admoestantes (partidários da seita de Armínio, teólogo holandês do século XVII), e Afrikander (indivíduo de origem holandesa estabelecido no sul da África). Nem lhe escapam alguns novos termos artísticos - de que são exemplos neoimpressionismo (definido como estilo de uma escola moderna de pintura que procura empregar metodicamente a divisão da cor em elementos puros a fim de obter o máximo de brilho luminoso) e shakesperianismo (lembrando a maneira de compor de Shakespeare).

As excursões por essas áreas artísticas podem soar estranhas para um leitor desavisado, impressão que se desfaz quando se nota a compreensão subjacente do autor em relação à ciência e técnica. No sentido lato, há nesse empreendimento um aspecto de "como fazer" inerente à pintura, literatura e outras artes, que acompanha a criação estética - as artes exigem uma "ciência" ou "técnica", e para Taunay são os vocábulos correspondentes outras tantas peças lacunares nos inventários da língua portuguesa. 


\section{A Terminologia Zoológica e Cientifica em geral e a deficiência dos grandes Di- cionários Portugueses 5}

Taunay começa esse importante ensaio lexicográfico lembrando que seu conteúdo de crítica a Cândido de Figueiredo poderia parecer falta de generosidade devido à morte recente do autor do Novo Dicionário. Decidiu, porém, contrariar esse princípio, já que o autor português fora por ele pública e duramente criticado e, antes do falecimento do "douto dicionarista", os textos que compõem a presente obra já haviam aparecido na imprensa quando ele ainda era vivo, o que inclusive provocara por sua vez respostas do "ilustre filólogo" pela imprensa e em livro.

Trata-se de uma reimpressão de três ensaios, sendo o primeiro o mais alentado e de igual título (A Terminologia Zoologica e Scientifica em geral e a deficiencia dos grandes Diccionarios Portuguezes), seguido por A Chimica e a Physica no Novo Diccionario da Lingua Portugueza e, finalmente, um conjunto menor composto por: Algumas consideracões sobre a deficiencia do inventariamento da lingua no Brasil; Os vocabulários incompletissimos de nossa fauna e nossa flora; Necessidade premente de um diccionario brasileiro da lingua portugueza typo Webster.

Mesmo com esse preâmbulo respeitoso, Taunay não tarda já no prefácio a verdadeiramente espinafrar Cândido de Figueiredo, não tanto pelas omissões de que não escapa nem mesmo, como mencionado atrás, o que considera o melhor dicionário da época, o de Caldas Aulete, mas principalmente pelos seus erros: "no grande léxico figueiredeano abundam os dislates e são freqüentes até as parvoíces". Julgamento severo, mas que Taunay pretende demonstrar ser completamente justificado.

Começando pela zoologia, aponta Taunay um dos motivos fundamentais para as falhas do dicionarista português: trata-se de um erro de base, pois Figueiredo se pauta por classificações zoológicas muito obsoletas, que remontam às de Cuvier (de 1812), durante a época napoleônica. Seguem-se inúmeros exemplos disso, sendo pitoresca a citação de lombriga, que Cândido aplica indistintamente tanto a um nematoide quanto a um anelídeo. Conclui com ironia ferina Taunay: "Só se em Portugal, pois no Brasil lombriga e minhoca são cousas diversíssimas".

Há erros graves de lógica das classificações, também apontados, como quando Cândido de Figueiredo define uma determinada família de ofídios dizendo que tem "por tipo a cobra", que é o nome genérico de todas as serpentes, trocando, portanto, o particular pelo geral. Com os insetos, o resultado é ainda pior, pois o dicionarista português omite a maioria das ordens e confunde gênero com ordem. Aponta então a segunda espécie de motivo para as falácias cometidas: é que Figueiredo se apoia para os brasileirismos em textos de jornais cariocas, também eivados de erros, ao invés de tomar como referência os cientistas brasileiros e suas obras. Mais grave ainda, continua Taunay, é que se poderiam ter evitado inúmeros disparates se ao menos tivesse sido

5 “A Terminologia Zoologica e Scientifica em geral e a deficiencia dos grandes Diccionarios Portugue-
zes", Revista do Museu Paulista, tomo XV, p. 277-383. São Paulo: Officinas do "Diario Official", 1927 
consultado um autor português "mais sério", como Maximiano de Lemos e sua Encyclopedia portugueza illustrada que, apesar de ultrapassada era bem mais atual e confiável do que os jornais utilizados. ${ }^{6}$

A nomenclatura ornitológica figueiredeana é outro desastre, para Taunay, como ilustrado com a definição dada por Cândido para arara como sendo uma espécie de papagaio, pois que em termos taxonômicos isto não tem sentido. A mesma inexatidão ocorre com os mamíferos: para o dicionarista português as jaguatiricas são "cães bravios do Brasil" e os furões são "mamíferos vermiformes". Já a irara seria um "quadrúpede do Brasil semelhante ao macaco". Vem à tona um terceiro indiciamento dos defeitos do dicionarista português: é a relutância em incorporar a contribuição do saber brasileiro, resultante da pesquisa de estudiosos locais.

O cúmulo da indignação do autor vem na parte entomológica com o verbete guaxupé, uma espécie de abelha silvestre brasileira, inserida por Figueiredo invocando uma citação justamente do romance Inocência. ${ }^{7}$ Neste, há uma passagem em que um personagem diz estar com sua cabeça "como um cortiço de guaxupés", passagem que leva o dicionarista português a definir guaxupé como sendo uma espécie de penteado.

Há outros erros igualmente saborosos, que Taunay denuncia sem clemência, muitos deles previamente expostos por ele na imprensa, mas que Figueiredo se obstinou em ignorar na nova edição do seu dicionário. Vale lembrar na parte ictiológica do dicionário do português a definição de boto como sendo um peixe semelhante ao atum, não obstante ser um cetáceo, aliás, o mesmo erro cometido com golfinho, que se torna um "peixe marinho". Idem, para a definição de carrapato como sendo um tipo de crustáceo. Inútil para Taunay, portanto, esperar da parte de Cândido o que seria uma sutileza taxonômica como a diferenciação dos tripanossomos, pois há vários, pois lembra que aquele que causa o mal de Chagas é diferente do que causa a doença do sono, e assim por diante.

A química do Novo Dicionário é igualmente plena de nomenclaturas obsoletas e objeto de reparos mordazes. Como exemplos dos erros citados por Taunay, de forma devastadora, é digna de registro a confusão que iguala sulfitos (compostos de $\mathrm{SO}_{3}$ ) e sulfatos (compostos de $\mathrm{SO}_{4}$ ), fosforoso (composto de $\mathrm{PO}_{3}$ ) e fosfórico (composto de $\mathrm{PO}_{4}$ ). Abisma-se Taunay que para Cândido de Figueiredo ozônio seja definido como um cheiro e não uma substância, num caso típico de troca do efeito pela causa, e que o elemento rádio seja uma substância que se encontra no elemento bário, destruindo-se assim a pró-

\footnotetext{
${ }^{6}$ Maximiano Augusto de Oliveira Lemos (égua, 1860 - $\underline{\text { Porto, }} \underline{1923}$ ), professor universitário e médico, docente da cadeira de História da Medicina, exerceu o cargo de diretor da Faculdade de Medicina e de vice-reitor da Universidade do Porto. Foi redator dos Arquivos de História da Medicina Portuguesa, da Gazeta dos Hospitais do Porto e da Gazeta Médica do Porto, sócio da Sociedade de Medicina Cirúrgica do Porto, a que presidiu, sócio correspondente da Academia das Ciências de Lisboa, da Sociedade de Medicina da Baía, da Sociedade Alemã de História da Medicina e da Academia de Ciências Naturais de Leipzig.

${ }^{7}$ Inocência (1872) é, possivelmente, a obra literária mais conhecida do pai de Afonso Taunay, o músico, historiador, cientista e escritor Alfredo, Visconde de Taunay.
} 
pria noção de elemento químico. Há grande confusão na física do Novo Dicionário também, como quando Cândido iguala raios catódicos com os raios X, ou considera hertriano como "uma variedade de telégrafo". Para Taunay essa física não é nada "católica" ...

Um reparo indignado é o que reserva o autor para a ausência do termo ecologia, já então dicionarizado na Inglaterra, França, Espanha, nos EUA, e mesmo em Portugal (Encyclopedia Portugueza Illustrada), e fartamente utilizado em textos científicos brasileiros. Taunay já havia chamado a atenção de Figueiredo para essa lacuna na edição anterior do seu dicionário, mas este aparentemente nunca ouvira falar de ecologia e se recusou a incorporá-la exigindo que Taunay justificasse tal inclusão. Com humor, aponta ainda a definição dada por Figueiredo para aeroplano: "aparelho aerostático movido a vapor e formado de planos ou de lâminas e de um motor (inventado recentemente, em 1896, por Langley)", ignorando não só a força motriz de combustível, mas também outros inventores contemporâneos, como Santos Dumont e os irmãos Wright, entre outros.

No conjunto ensaístico final, Taunay levanta o problema dos muitos brasileirismos e regionalismos brasileiros, todos ainda por dicionarizar. Considera a importância do papel neologizador da imprensa, que contribui criando palavras novas constantemente, e lamenta a falta de um levantamento amplo da linguagem popular para os dicionários. Centrando sempre seu foco nas omissões de Figueiredo, critica-o por registrar para barragem apenas o que entre nós se conhece como cercado de peixe, ignorando o sentido brasileiro de represa, como por exemplo nas diversas "barragens da Light" no Rio de Janeiro e São Paulo, para geração hidrelétrica.

Taunay concorda com os que afirmam que o "futuro da língua portuguesa... está no Brasil e não em Portugal" e cita o autor do Novo Vocabulário Nacional, Carlos Teschauer, do Rio Grande do Sul, assim como Oliveira Lima, a propósito da recente comemoração (1922) do centenário da Independência brasileira, autores para quem uma nova nacionalidade exige não somente uma literatura própria, mas também uma língua diferenciada. ${ }^{8}$ Ressalta assim Taunay com seu trabalho lexicográfico um sentimento de nacionalismo frente a uma atitude que recordava o modelo de subjugação da colônia à metrópole.

Reclama enfim a necessidade no Brasil de um dicionário moderno e abrangente, impecável e qualificado cientificamente graças a colaboradores escolhidos e numerosos, para o qual aponta como modelo o famoso Webster Dictionary norte-americano, certamente diferente do dicionário de Cândido de Figueiredo - um clamor nacional que, como é sabido, ainda persistirá por muitas gerações.

\footnotetext{
${ }^{8}$ Carlos Teschauer (Birstein, 1851 - São Leopoldo, $\underline{\text { 1930) }}$ ), professor, historiador e folclorista teutobrasileiro. Teschauer tornou-se jesuíta em 1874 e viajou para o Brasil em 1880, fixando-se no Rio Grande do Sul, onde se tornou um grande estudioso das tradições gaúchas e autoridade em matéria de história, cultura indígena e etnografia daquele Estado. Manoel de Oliveira Lima ( $\underline{\text { cife, }}, \underline{1867}$ - Washington, 1928) foi notável escritor, crítico literário, diplomata, historiador e jornalista brasileiro.
} 


\section{Inópia científica e vocabular dos grandes dicionários portuguezes9}

Taunay começa esse alentado ensaio lexicográfico sobre a inópia (ou pobreza) científica e vocabular dos dicionários lusitanos, situando-o como continuação de sua anteriormente já citada Terminologia Zoologica e Scientifica em geral e a deficiencia dos grandes Diccionarios Portuguezes (1927). A obra é dedicada ao editor e bibliófilo Felix Pacheco, que a publicara anteriormente em seu "Jornal do Commercio". Nela são retomados e aprofundados temas que Taunay vinha expondo na imprensa desde 1909, a saber, o tratamento vocabular deficiente dos dicionários de Portugal para cobrir tanto o próprio idioma da ex-metrópole quanto as particularidades da língua falada no Brasil. Segundo o autor, à época havia cerca de cem mil palavras brasileiras que os dicionaristas portugueses simplesmente ignoravam.

O principal alvo das críticas é mais uma vez Cândido de Figueiredo, a quem Taunay acusa de misoneísmo, (aversão ao novo e ao progresso). Com a sua habitual ironia, para Taunay o Novo Dicionário de Figueiredo, "o inventário máximo de nossa língua, é o mais deficiente dos arrolamentos". Para além de tudo, denuncia-lhe a incoerência metodológica, ao registrar palavras por certos critérios, inexplicavelmente ignorados para recusar outras, como no caso de sociologia. Um aspecto interessante é o apontamento de arcaísmos lusos, que se encontram redivivos pelo Brasil, inclusive em velhos municípios paulistas à beira do Tietê. É o caso até de latinismos como o verbo hostar, significando "hospedar". Por outro lado, chama a atenção para modismos que vão se impondo, como é o caso da palavra cômputo, que antes era usada "até por analfabetos" e perdeu lugar para conta.

É particularmente notada e novamente criticada a ausência de palavras da zoologia brasileira, como os ofídios jararaca, urutu, jibóia, coral, caninana, para a identificação das quais Taunay contava com diversos colaboradores na zoologia e medicina, com nomes destacados como o do médico sanitarista Artur Neiva. Com erudição, o autor busca campos diversos onde é lacunar ou errôneo o registro vocabular de Cândido de Figueiredo, como na heráldica, em que se vale do autor português Santos Ferreira e de seu Armorial Português, ou na serralheria, para reclamar de um termo não averbado c por Figueiredo como puxador (ferragem de gaveta).

Taunay não se limita à já alentada deficiência de termos científicos e tecnológicos dos dicionários. Como exemplo disso, faz uma divertida excursão às palavras cuja origem é incerta e que acabam tendo uma etimologia fantasiosa, abonada em descuido por alguns dicionaristas de sua época, como larápio, para a qual era comum se propor ser formada a partir da abreviação do nome de um suposto magistrado romano corrupto, Lucius Antonius Rufus Appius... Com igual senso de humor censura os autores brasileiros que fazem uma "mudagem de linguança", trocando as desinências substantivas e adjetivas.

${ }^{9}$ Inopia scientifica e vocabular dos grandes diccionarios portuguezes. Separata do tomo XVII, $2^{\text {a }}$ parte (182 p.), Revista do Museu Paulista. São Paulo: Imprensa Oficial, 1932 
Na sua defesa de "caçada aos brasileirismos", Taunay quer urgência para demonstrar "para honra da inteligência nacional" que o português falado no Brasil não se limita aos 130 mil vocábulos anotados por Figueiredo, quando o inglês já arrolou 500.000 e o alemão 400.000 vocábulos. Para isso, os brasileiros deveriam chegar logo a "zurrar", fazendo novamente galhofa, desta vez com o célebre marco terminal na última letra do léxico. Nosso futuro "Webster" teria então que acabar aceitando palavras como encrenca, cuja etimologia Taunay propõe ser do espanhol "enclenca", apesar dos que torciam o nariz para uma origem tão vulgar como a castelhana.

Em determinada altura, o autor conta mais um motivo para justificar sua implacável birra com Cândido de Figueiredo: soubera que o padre jesuíta português João Serafim Gomes, também dicionarista, teve suas pesquisas apreendidas por ocasião da revolução republicana de 1910 em Portugal, que perseguiu o clero monarquista. Logo depois, porém, reaparecem seus verbetes na $2^{\mathrm{a}}$ edição do Novo Dicicionario de Figueiredo, aliado republicano, sem ter mencionado o verdadeiro autor.

Depois da persistente denúncia de lacunas e erros por parte de Figueiredo, Taunay passa a historiar o surgimento de dicionários das línguas europeias, inclusive a portuguesa, desde o início do período moderno. Lembrando dos esforços jesuíticos nesse campo, lamenta que a coroa portuguesa, ao contrário da espanhola, não tivesse permitido o funcionamento de tipografias no Brasil, caso contrário teríamos dicionários de nossa antiga "língua geral". Entre os autores apontados, desponta como o primeiro colaborador original para a língua lusitana um estrangeiro, Rafael Bluteau, de quem Taunay traça uma interessante biografia. Para ele, a obra de Bluteau (1712) foi a primeira a dicionarizar brasileirismos, ainda que muito poucos; e, apesar das imperfeições, Bluteau era enciclopédico e ainda mais exato do que muitos de seus lexicógrafos sucessores, como Moraes. E nas palavras em que aquele dicionário é inexato, como nos termos médicos e biológicos, vê Taunay não motivos para vituperação, mas sim fontes para estudar os conhecimentos científicos tal como se apresentavam no começo do século XVIII.

"E haverá coisa mais difícil do que definir?", pergunta Taunay, antes de comentar outro dicionário, o de Frei Bacelar (1783), cujas definições risíveis chegam a ser até pitorescas, como "bacharel: falador formado", ou "boca: buraco da cara". O lugar de primeiro lexicógrafo brasileiro seria de Antônio de Moraes e Silva, cujo dicionário teve a primeira edição portuguesa em 1789, mas a que se sucederam várias edições e continuava sendo considerado uma autoridade na língua. Taunay recapitula e comenta com detalhes sua biografia acidentada, assim como a do segundo dicionarista brasileiro, Luís Maria da Silva Pinto, cuja obra (1839), comenta, ficou plena de omissões e erros.

Uma série de outros dicionaristas portugueses são historiados: Francisco Solano Constâncio, bom para as etimologias, apesar de não sê-lo para as explicações vocabulares, com exceção de suas definições científicas, adequadas para sua época - os demais dicionaristas, diz Taunay, parece escreverem no tempo dos alquimistas, ignorando a química e física que lhes eram contemporâneas; Eduardo de Faria, julgado péssimo; Dom José de Lacerda, muito deficiente; Frei Domingos Vieira, com seu Thesouro da lingua portugueza, obra muito desigual, devido a ter nascido "de diversos escritores de conhecimentos não muito afinados entre si”'. 
Por último dedica o autor sua atenção nesse ensaio para o dicionário de Caldas Aulete, que para ele supera de longe Cândido de Figueiredo. Segue-se a apreciação relativamente negativa, quanto ao vocabulário, da Enciclopédia portuguesa ilustrada, de Maximiano de Lemos - mas que se tivesse sido consultada por Figueiredo ter-lhe-ia evitado um sem-número de erros crassos. Igualmente deficiente é julgada a Enciclopédia Jackson, que em geral Taunay afirma copiar Figueiredo, bem como o faz o Lello Universal, que na época estava começando a ser dado a público, e se tornou obra muito difundida no Brasil (sendo inclusive publicada e colecionada em fascículos vendidos em jornaleiros).

\section{Algumas conclusões}

A atividade lexicográfica de Afonso Taunay não passou desapercebida em sua época. Foi um dos pontos mais comentados no discurso de sua recepção na Academia Brasileira de Letras, feita por Roquette-Pinto em 1930, que destacou sua contribuição para o registro dicionarizado de vocábulos populares, bem como sua atitude nacionalista, face à hegemonia das obras lusitanas, no que concerne à suposta pureza da língua portuguesa. ${ }^{10}$ Taunay assinala a contribuição negra, índia e dos imigrantes, sobretudo italianos, espanhóis e alemães.

Tampouco deixou de assinalar Roquette-Pinto a contribuição de Taunay para a atualização da terminologia científica e técnica. É, portanto, uma tarefa reconhecer a importância deste legado e a necessidade de dar continuidade a este esforço, sabendo que atualmente a língua inglesa já registra um milhão de vocábulos, o dobro daqueles contidos no alerta de Taunay.

${ }^{10}$ Edgard Roquette-Pinto (Rio de Janeiro, 1884 - Rio de Janeiro, 1954), médico legista, professor, escritor, eugenista, antropólogo, etnólogo e ensaísta brasileiro, membro da Academia Brasileira de Le$\underline{\text { tras, }}$ é considerado o pai do rádio brasileiro com a primeira transmissão no centenário da Independência, em 1922. Criador da Rádio Sociedade, com o intuito de difundir a educação por este meio, por volta de 1923. 